\title{
ASSESSMENT OF RADARSAT-2 HR STEREO DATA OVER CANADIAN NORTHERN AND ARCTIC STUDY SITES
}

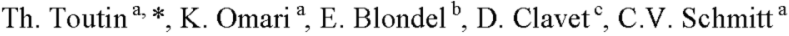

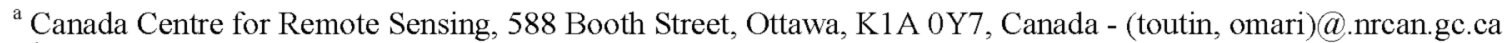 \\ ${ }^{\mathrm{b}}$ Gismatix Inc., 1475 Cumberland Ridge Drive, Cumberland, K4C 1E1, Canada - enriqueblondel@rogers.com \\ ${ }^{\mathrm{c}}$ Centre for Topographic Information, 2144 King Street West, Sherbrooke, J1J 2E8, Canada - Clavet@.nrcan.gc.ca
}

Working Groups I/2, III/1, III/4, III/5

KEY WORDS: Radarsat-2, SAR, High-resolution, Geometric modeling, DSM, Canadian Arctic

\begin{abstract}
:
Digital surface models (DSMs) extracted from high-resolution Radarsat-2 (R2) stereo images using a new hybrid radargrammetric modeling developed at the Canada Centre for Remote Sensing are evaluated over two Canadian northern and arctic study sites. Because the new hybrid model uses the full metadata of R2, it does not require any ground control point. The first study site in the north of Quebec is used for the scientific validation where accurate checked data (dGPS, lidar) is available. The second study site in the Arctic (steep relief and glaciated surfaces) is challenging for the operational evaluation of topographic mapping capabilities of R2. For the first study site, the bias and elevation linear errors with 68 percent confidence level (LE68) of R2 stereo-extracted DSM compared to lidar data were computed over bare surfaces: LE90 of $3.9 \mathrm{~m}$ and no bias were achieved. For the second study site the comparison was performed between the R2 DEM and ICESat data. A negative 18-m bias was computed and certainly result suggests a bias in the stereo-model of R2 and thus in the metadata used in the model computation because there is few temporal variation in the data acquisition (R2 and ICESat). LE68 of $28 \mathrm{~m}$ was obtained. However, the differential melting and thinning depending of the glaciers elevations and planimetric surging of glacier tongues with less accumulation of debris and moraines, a lower LE68 of around $20 \mathrm{~m}$ could be expected. In addition to evaluate the potential of R2 over ice bodies, which generally have low slope relief and because the errors are strongly correlated with slopes, other statistical results of elevation differences were also computed: LE68 of $15 \mathrm{~m}$ was obtained over ice fields with $0-5^{\circ}$ slopes while a little more than $20-\mathrm{m}$ over less than $30^{\circ}$ slopes was achieved.
\end{abstract}

\section{INTRODUCTION}

\subsection{Canadian Context}

Canadian Arctic suffers from poorly-known relief. In addition, the surface state of glaciated regions is rapidly evolving due to snowfall, snow transport by wind and/or surface melt, remote sensing data (Synthetic Aperture Radar (SAR) or optical) used to retrieve the topography must be acquired with the shortest possible time interval to maximize their coherence or correlation. This is also important because the flow of the glacier (up to a few meters per day) during this time interval can bias the topographic measurement.

Stereo radargrammetry using synthetic aperture radar (SAR) data can thus be an appropriate solution, even with multi-date across-track capability, due to different SAR advantages specific to ice regions. First, the backscatter of SAR sensors is more dependent of the rugosity or the dielectric component, which enable more radiometric contrast over ice fields with supraglacial debris, rock glaciers, moraines, etc. Second, the SAR sensors are operated in all-weather conditions and not dependent of the solar illumination conditions, which thus cancelled the large shadowed areas with optical data in high latitudes. Third, the convergence of heliosynchronous orbits to North/South poles combined with a large range of look angles $\left(20^{\circ}-60^{\circ}\right)$ gives thus a strong advantage to drastically reduce the temporal variations to few days between the multi-date stereoimages acquired in the highest latitudes. Fourth, the new satellite SAR sensors have now high-resolution (HR) capabilities (sub- to few meters), and are dedicated toward operational applications.

1. Due to the remote and harsh environments of the Canadian Arctic, the 3D geometric processing of SAR images should require no ground control points (GCPs) collected by users for the operational applications. A new hybrid radargrammetric model recently developed for Radarsat-2 (R2) at the Canada Centre for Remote Sensing was thus used for the stereo-modeling and the generation of digital surface models (DSM) (Toutin and Omari, 2011). In order to evaluate the performance of the process in a well-controlled environment as well in an operational environment, two Canadian northern study sites were used: the first one for the scientific validation and the second one for the operational evaluation in Arctic.

\subsection{Canadian Northern Study Sites}

The first study site is located north of Quebec City, Quebec, Canada and spans different environments: urban and residential, semi-rural and forested (Figure 2). The elevation ranges almost from $10 \mathrm{~m}$ in the city in the southeast to around $1000 \mathrm{~m}$ in the Canadian Shield in the north. The northern part is a hilly to mountainous topography $\left(5^{\circ}-30^{\circ}\right.$ slopes $)$ mainly covered with forests (deciduous, conifer and mixed) while the south part is a semi-flat topography $\left(0^{\circ}-5^{\circ}\right.$ slopes $)$ with urban and residential areas.

\footnotetext{
* Corresponding author.
} 
The second study site is located in the Baffin Island, Nunavut at approximately $70^{\circ} 50^{\prime} \mathrm{N}$ and $71^{\circ} 30^{\prime} \mathrm{W}$ (Figure 1). There is no vegetation cover, except small plants. More than $80 \%$ is covered by ice fields with cirque glaciers (permanent icecovered mountains), outlets and valley glaciers and glaciers tongues surrounded by spectacular fiords with $70^{\circ}-90^{\circ}$ cliffs of 500-800 m height. Bare surface mountains also with steep slopes surround the ice fields and glaciers. The valley glacier in the south-east is about $1-\mathrm{km}$ wide with up-to- $4^{\circ}$ slopes surrounded by $600-\mathrm{m}$ height bare surface and cirque glaciers. The elevation ranges from sea level to $1840 \mathrm{~m}$ and the slopes vary from $0^{\circ}$ to $90^{\circ}$ at fiord cliffs, illustrating a very challenging environment (in terms of land cover and relief).

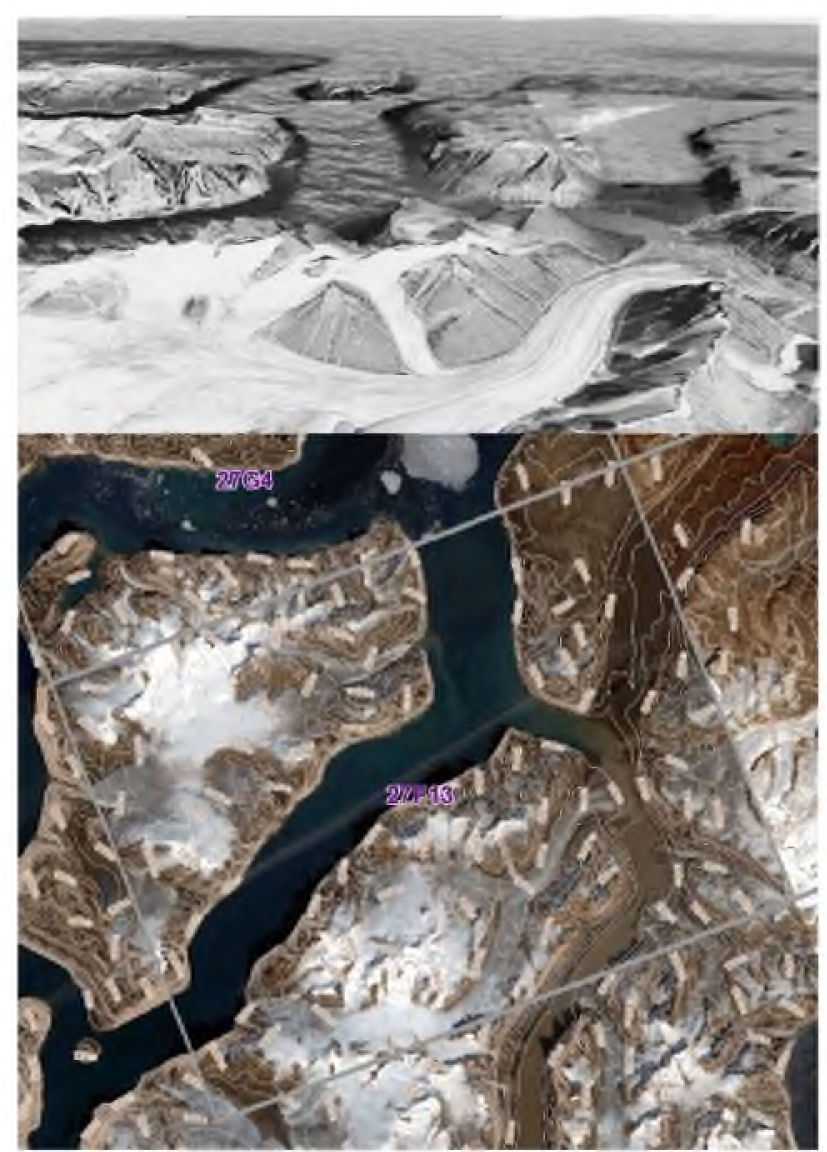

Figure 1. Top: Perspective view from south to north of the second study site, generated with Google Earth using images from TerraMetrics and WorldView. (C) 2010 Google and Images C) 2010 TerraMetrics and DigitalGlobe.

Bottom: Ortho-rectified Landsat-7 with 1:50,000 map sheet grid

\subsection{Data Set}

For the first study site, the R2 SAR data set included two stereo images ( 20 by $20 \mathrm{~km}$ ) acquired September 10 and 14, 2008 with the C-band ultra-fine (U) mode ( 1 by 1 look; $1.6-2.4$ by $3 \mathrm{~m}$ resolution) in VV polarization from descending orbits with view angles of $30.8^{\circ}-32^{\circ}$ (U2 Figure 1) and $47.5^{\circ}-48.3^{\circ}$ (U25) at the near-far edges, respectively.

The reference cartographic data included ground points, mainly road intersections and electrical poles, collected from a differential Global Positioning System (dGPS) survey in
November 2008 with 3-D ground accuracy of $10-20 \mathrm{~cm}$. The collected points were used either as independent check points (ICPs) to quantify/validate the new hybrid model accuracy. In addition, $10-\mathrm{cm}$ accurate cloud-point data (first echoed return) were obtained froma lidar survey collected by GPR Consultants.

For the second study site, the R2 stereo images were acquired in 2009 from descending orbit with the ultra-fine mode (U mode with $3-\mathrm{m}$ resolution) in HH polarization: $\mathrm{U} 12$ and $\mathrm{U} 26$ (20 by $20 \mathrm{~km} ; 1.6$ by $2.5-3.0 \mathrm{~m}$ pixel spacing) on September 28 with $38.83^{\circ}-39.84^{\circ}$ right look angles and October 09 with $48.12^{\circ}$ $48.93^{\circ}$ look angles, respectively (Figure 3 ). The radiometry of these stereo-data are however, dominated by the geometric issues due to high relief with no vegetation cover: more severe layover in U12 over the east-oriented slopes and more occluded areas over the west-oriented slopes in U26. In fact, the southnorth curved land-water boundary of the left island represents the cliff layover over the ocean, and not the "smoother" coast line of a glacial-eroded fiord, and part of the low lands along this coastline cliff thus "disappeared". On the other hand, it is almost impossible to discriminate the true water-land boundary for the opposite coastline cliffs due to the SAR shadow/occluded areas.

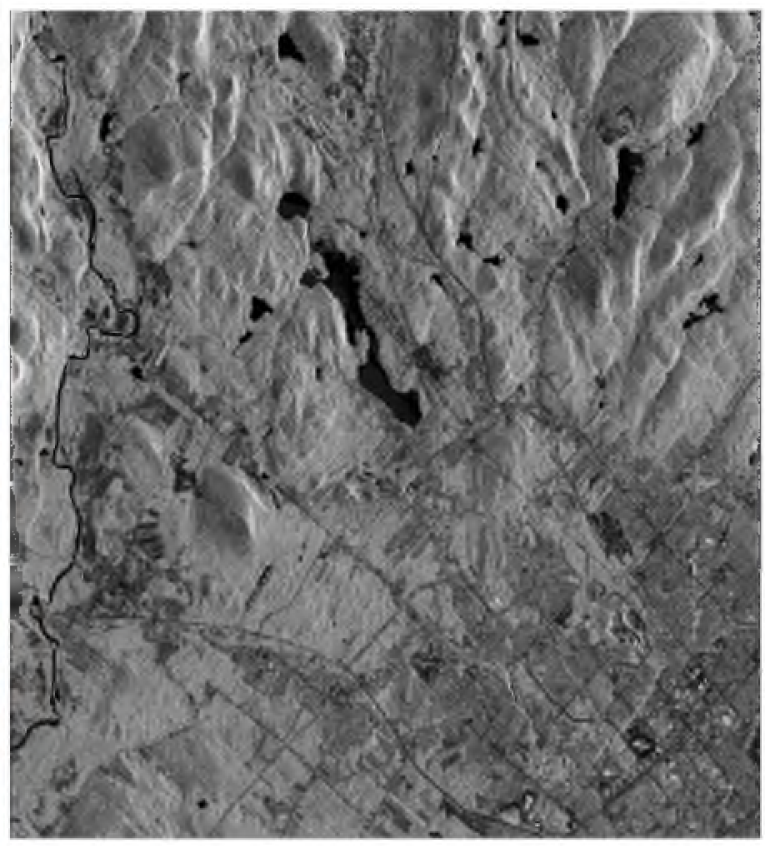

Figure 2. R2 ultra-fine mode image U2 of the $1^{\text {st }}$ study site. "Radarsat-2 Data @ MacDonald, Dettwiler and Associates Ltd (2008) - All Rights Reserved" and Courtesy of CSA

We can notice on Figure 3 that all coastline cliffs and most cirque glaciers as having strong slopes $\left(60^{\circ}-90^{\circ}\right)$ while the ice fields with their outlet glaciers have in general lower slopes $(0-$ $20^{\circ}$ ). However, steep $20^{\circ}-90^{\circ}$ slopes also occurred in some ice fields.

The lidar ICESat data (ascending and descending tracks) over the 27F13 map sheet was extracted from GLA14 product (L2 Global Land Surface Altimetry Data) Release 28, 29 and 31 over the full life cycle of the mission 2003-2008. Conversion to Canadian reference systems was applied to translate ICESat GLAS data into orthometric heights. ICESat data points were spatially filtered: (1) horizontally to remove redundant values 
within 100-m radius, and (2) vertically within 1 -arcsec grid spacing (around $25 \mathrm{~m}$ at $70^{\circ}$ latitude), to remove potential elevation anomalies resulting from clouds or valley fog above $50 \mathrm{~m}$ above sea level.

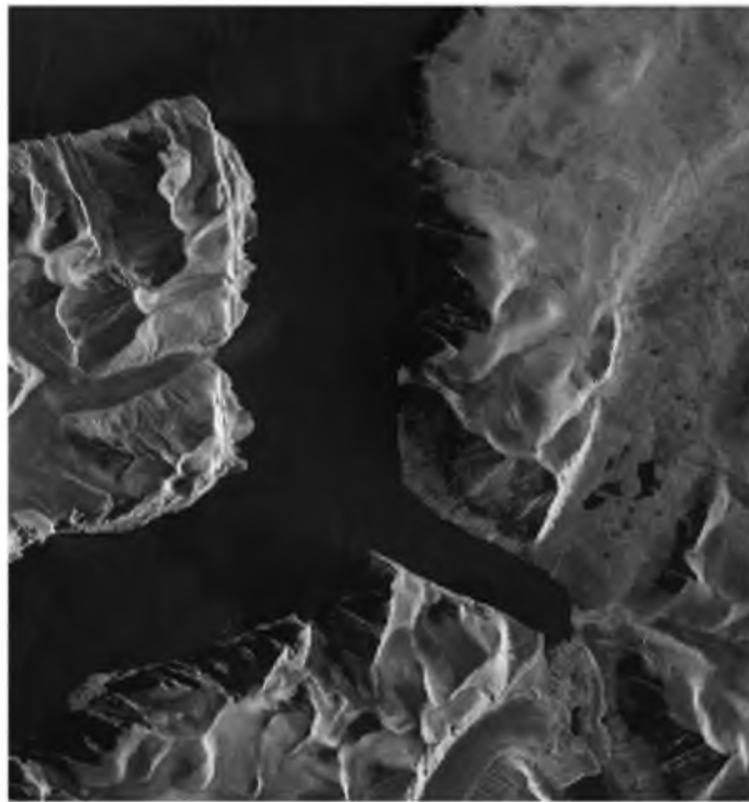

Figure 3. R2 ultra-fine mode image U12 of the $2^{\text {nd }}$ study site "Radarsat-2 Data @ MacDonald, Dettwiler and Associates Ltd (2009) - All Rights Reserved" and Courtesy of CSA

\section{DESCRIPTION OF THE PROCESSING STEPS}

The processing steps for DSM generation with HR SAR stereoimages were previously addressed and documented (Toutin, 2010). The new hybrid Toutin's model developed for the radargrammetric processing of R-2 at CCRS does not require any GCP collected by the user (Toutin and Omari, 2011): it only uses the information in the meta-data of the images for computing its parameters. The hybrid model has been proven to be $25-\mathrm{cm}$ precise (Toutin and Chénier, 2009), and the accuracy $(1 \sigma)$ of the results in stereoscopy was better than one pixel with one-pixel biases in the three axes. The main processing steps are:

1. Acquisition and pre-processing of the SLC SAR images and metadata;

2. Collection of 60 ICPs from the dGPS survey;

3. Computation of hybrid models and their validation with ICPs (systematic and random errors);

4. Elevation extraction used a 7-step hierarchical greylevel image matching performed on the quasi-epipolar stereo-images and geocoding of this epipolar DSM (Ostrowski and Cheng, 2000);

5. Evaluation (systematic and random errors) of the geocoded DSMs with the lidar elevation data.

\section{RESULTS AND DISCUSSIONS}

Results are first related to the systematic and random errors (1) of the hybrid radargrammetric models computed over ICPs and (2) of the stereo-extracted DSMs computed over the lidar elevation data.

\subsection{Radargrammetric model evaluation}

Because there was no control data in the second study site, Table 1 only summarizes the results of the radargrammetric modeling computation for the first study site and data set previously described: the errors (bias and standard deviation, Std in meters) computed over 60 ICPs providing independent and unbiased evaluations of the modeling accuracy. Biases of one pixel (or half SAR resolution) or slightly worse for Ydirection are obtained. Similarly, Std results in the order of one pixel are better for X-direction. It is certainly due to the better knowledge of the range direction than the azimuth direction corresponding to the satellite displacement. Both results in Zdirection are also very good versus the SAR resolution and the same-side stereo-geometry. These results are comparable $(10 \%$ difference), but a little worse in the Y-direction, to the original radargrammetric model computed with user-collected GCPs (Toutin and Chenier, 2009). On the other hand, the small lost in accuracy for the hybrid model is compensated by the gain of processing the stereo-images without GCP.

\begin{tabular}{|c|c|c|c|c|c|}
\hline \multicolumn{3}{|c|}{ Bias (m) } & \multicolumn{3}{c|}{$\mathrm{Std}(\mathrm{m})$} \\
\hline $\mathrm{X}$ & $\mathrm{Y}$ & $\mathrm{Z}$ & $\mathrm{X}$ & $\mathrm{Y}$ & $\mathrm{Z}$ \\
1.8 & 2.6 & -2.7 & 0.93 & 1.33 & 2.34 \\
\hline
\end{tabular}

Table 1. Modeling results over $60 \mathrm{ICPs}$ for the $1^{\text {st }}$ study site: Bias and standard deviation (Std) in metres

\subsection{DSM evaluation}

3.2.1 First study site: Visually, the DSM (Figure 4) with only few percent of mismatched areas is smooth and well describes the macro-topography and the macro linear trends with mountains and valleys, enhancing the structural geological framework in the northwest-southeast direction. The mountains and valleys are generally smooth, being a good representation of a Precambrian geomorphology (smoothed-glacial and eroded topography).

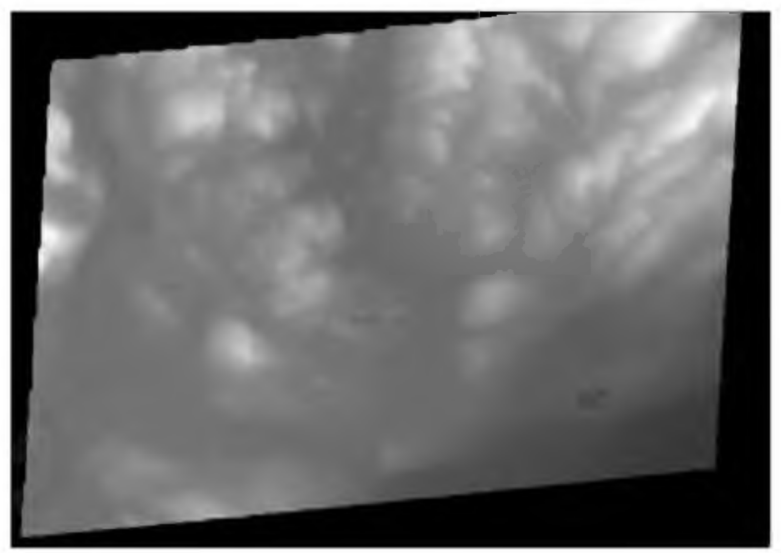

Figure 3. R2 DSM of the first study site

The quantitative evaluation was performed over the coverage of the lidar data, being on the half eastern part of DSM (Figure 3 ). The computed difference between R2 DSM and lidar data (Table 2) would be still representative of the overall DSM: all relief (flat to mountainous; all slopes and azimuths) and all land covers (urban, semirural, bare soils, and forested areas) of the study site were embraced. 


\begin{tabular}{|c|c|c|}
\hline Surfaces & Bias $(\mathrm{m})$ & LE68 $(\mathrm{m})$ \\
\hline All surfaces & 6.6 & 7.5 \\
Bare surfaces & 0.1 & 3.9 \\
\hline
\end{tabular}

T'able 2. Diflerences between lidar data and R2 I)SM over different surface types: Bias and LE68 in metres

However, the results computed over the full lidar coverage (Table $2,1^{\text {st }}$ line) do not reflect the true DSM accuracy since the dominant source in the error budget comes from: (1) the footprint and penetration in the vegetated cover are different for both sensors (SAR and lidar); and (2) the compared stereo-SAR and lidar points are not at the same elevation in the vegetated cover $(70 \%$ of lidar coverage). These errors are thus reflected in the $6.6-\mathrm{m}$ bias and $7.5-\mathrm{m}$ LE68. To have the true elevation accuracy, the error evaluation was performed only on bare surfaces (Table 2, $2^{\text {nd }}$ line) where the stereo $\mathrm{S} \wedge \mathrm{R}$ and lidar points were at the same ground elevation. Almost no bias and 3.9-m LE68 is thus obtained. The bare surfaces were also representative of the full terrain relief because they occur not only on low lands and slopes but also in the high lands and slopes (mainly, in the northeast).

3.2.2 Second study site: The R2 DEM is displayed in Figure 5 with the ice field and glaciers boundaries (in red) and supraglacial debris and morianes boundaries (in blue). The DEM looks relatively smooth over the ice fields, even with the backscatter homogeneity in ice covered areas, mainly due to the choice of the matching parameterization. In addition, the planned R-2 acquisition at the end of the melt season increased the roughness and thus the radiometric contrast. During this period, the ice covered by supraglacial debris and dust offered its maximum degree of surface texture. It is the main reason of the few percent mismatched areas. Conversely, the DEM looks very strange along all coast cliffs displaying over $50^{\circ}$ slopes and large geometric and radiometric differences between the two images. The combination of these geometric and radiometric distortions, which only occurred in such a challenging Arctic study site, would impede any image matching.

The quantitative evaluation was performed with ICESat lidar. The height measurements of land surface will be the prime interest for DFM quality assessments (7wally et al., 2002). While the total number of ICESat data from ascending and descending orbits is limited to thousand points (Figure 5, blue and red footprints), it will be more limited because ICESat accuracy strongly degrades with slopes. Because the primary goal of ICESat is to measure inter-annual and long-term variations in the polar ice-sheet elevation and volume of Greenland and Antarctica, there were no absolute validation results over more than $5^{\circ}$ slopes. Consequently as a function of the expected accuracy for R2 DSM, we only considered for R2 DSM evaluation the ICESat data on slopes less than $30^{\circ}$ (Figure 5 , blue footprints). Table 3 gives the computed difference between R2 DSM and ICESat data for the total DSM (715 points).and only on ice ficlds (386 points).

\begin{tabular}{|c|c|c|c|}
\hline Surfaces & $\begin{array}{c}\text { ICESat } \\
\text { points }\end{array}$ & Bias (m) & LE68 $(\mathrm{m})$ \\
\hline All DSM & 715 & -17 & 31 \\
Ice fields & 386 & -18 & 28 \\
\hline
\end{tabular}

Table 2. Differences between ICFSat blue footprints and R2 DSM over different surface types: Bias and LE68 in metres

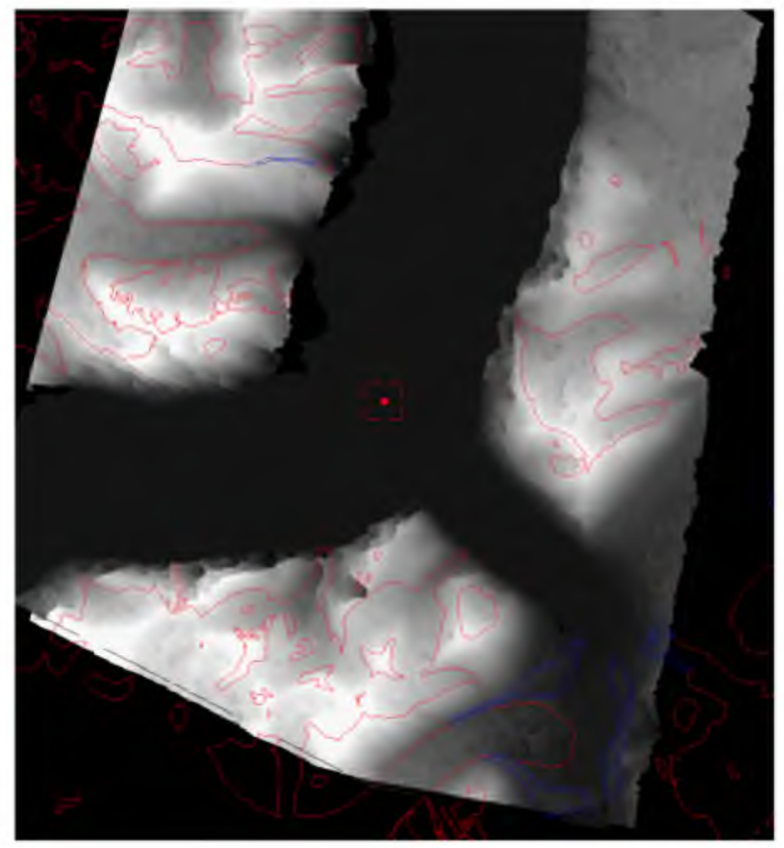

Figure 4. R2 DSM of the second study site with ice field and glacier boundaries (in red) and supraglacial debris and moraine boundaries (in blue) overlaid.

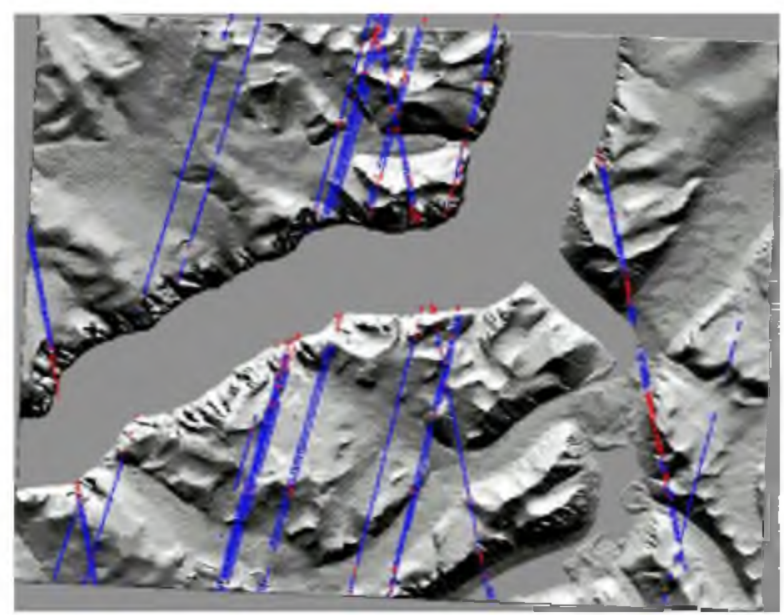

Figure 5. Ascending and descending ICESat tracks overlaid over a shaded relief image: blue and red footprints are below and over $30^{\circ}$ slopes, respectively.

The two biases suggest a systematic error in the stereo-model of R-2 and thus in the metadata used for this stereo-model computation. The differential bias could be due to elevation change (thinning, surging) over ice lields because there is few years difference in the data acquisition. The LE68s are relatively similar but worse for all surfaces due to more steep slopes outside the ice field boundaries.

As mentioned before for the differential melting and thinning depending of the glaciers elevations and planimetric surging of glacier tongues with less accumulation of debris and moraines (Schwitter and Raymond, 1993), LE68 of R-2 DEM should thus be lower, around $20 \mathrm{~m}$. In addition, most of ice bodies 
have low slope relief, other statistical results of elevation differences between ICESat and R-2 DEM show that LE68 is strongly correlated with slopes: LE68 of $15 \mathrm{~m}$ was then computed over ice fields with $0-5^{\circ}$ slopes while a little more than 20 -m over less than $30^{\circ}$ slopes was achieved.

\section{CONCLUSIONS}

A new hybrid radargrammetric model, which does not require any user-collected GCP, was evaluated with R2 stereo-data for DEM generation over two study sites in the north of Canada. The first site having accurate control data enabled DSM accuracy of $3.9 \mathrm{~m}$ (LE68) with no bias over bare soils to be obtained.

The second site, a challenging environment with glaciated surfaces, fjords and steep relief, was used to evaluate the mapping potential of the method in the Canadian Arctic without control data. In this remote and harsh environment, DSM LE68 of $28 \mathrm{~m}$ with large bias $(-18 \mathrm{~m})$ was achieved over ice field. This major part of this bias is certainly due to a systematic error in the metadata and partially due the ice thinning.

While other methods using optical and SAR systems could achieved similar and even better results, this application demonstrated the capability of R2 to generate DSM with better than $20 \mathrm{~m}$ LE68 without collecting control data over ice bodies depending of the terrain slopes $\left(0-30^{\circ}\right)$ or around $15 \mathrm{~m}$ over ice sheets (slopes less than $5^{\circ}$ ). This new method increases the applicability of R2 to remote and harsh environments. The slight loss in accuracy when using dGPS is then compensated by the gain of no control data.

\section{Acknowledgements}

The authors would like to thank Paul Briand and the Canadian Space Agency for supporting and financing this research under their SOAR and GRIP programs. They also thank Dr. Philip Cheng and PCI for the adaptation of CCRS algorithms in OrthoEngine $^{\mathrm{SE}}$ of Geomatica.

\section{References:}

Toutin, Th., 2010. Impact of RADARSAT-2 SAR UltrafineMode Parameters on Stereo-Radargrammetric DEMs. IEEE Trans. Geosc. Remote Sens. 48(10), pp.3816-3823.

Toutin, Th. and R. Chénier, 2009. 3-D Radargrammetric Modeling of RADARSAT-2 Ultrafine Mode: Preliminary Results of the Geometric Calibration. IEEE-GRSL, 6(2), pp.282-286 \& 6(3), pp. 611-615.

Toutin, Th. and K. Omari, 2011. A new hybrid modeling for geometric processing of Radarsat-2 data without user GCP. Photogram. Eng. \& Remote Sens., 77(6), pp. 601-608.

Ostrowski, J.A. and P. Cheng, P., 2000, DEM extraction from stereo SAR satellite imagery. IEEE Proc. Geosc. Remote Sens., IGARSS 2000, Honolulu, Hawaii, Vol. 5, pp. 2176-2178.

Schwitter, M.P. and Raymond, C.F., 1993. Changes in the Longitudinal Profiles of Glaciers during Advance and Retreat. Journal of Glaciology, Vol. 39, No. 133, pp. 582590
Zwally, H.J., B. Schutz, W. Abdalati, J. Abshire, C. Bentley, A. Brenner, J. Bufton, J. Dezio, D. Hancock, D. Harding, T. Herring, B. Minster, K. Quinn, S. Palm, J. Spinhirne, and Thomas, R. 2002. ICESat's laser measurements of polar ice, atmosphere, ocean, and land. Journal of Geodynamics, 34( 34), pp. 405-445. 